\title{
Reducing stroke during cardiac surgery: Back flushing and manipulation is for plumbers, not surgeons
}

\author{
William M. DeCampli, MD, PhD
}

\footnotetext{
From The Heart Center, Arnold Palmer Hospital for Children; and the Department of Clinical Sciences, University of Central Florida College of Medicine, Orlando, Fla.

Disclosures: Author has nothing to disclose with regard to commercial support.

Received for publication March 22, 2017; accepted for publication March 23, 2017; available ahead of print April $22,2017$.

Address for reprints: William M. DeCampli, MD, PhD, Heart Center, Arnold Palmer Hospital, 80 W Miller St, Orlando, FL 32813 (E-mail: William.decampli@ucf.edu, William.decampli@orlandohealth.com).

J Thorac Cardiovasc Surg 2017;154:488-9

$0022-5223 / \$ 36.00$

Copyright (c) 2017 by The American Association for Thoracic Surgery

http://dx.doi.org/10.1016/j.jtcvs.2017.03.111
}

Central nervous system deficit, either transient or permanent, remains a major source of morbidity after cardiac surgery and is strongly associated with subsequent postoperative mortality. ${ }^{1}$ The causes are multifactorial, but embolism of atherosclerotic tissue from the aorta is considered a major contributor. Recent evidence for this contribution is supported by a large network meta-analysis, published a few months ago, that showed an odds ratio for stroke of 0.22 (95\% confidence interval, 0.15-0.33) when an aortic "no touch" technique, as opposed to conventional aortic manipulation and cannulation, is used. ${ }^{2}$ The advantage of "no touch" was also significant when compared with the "Heartstring" approach, both performed without cardiopulmonary bypass (CPB) (odds ratio, $0.5 ; 95 \%$ confidence interval, $0.29-0.85$ ).

When CPB is used, cannulation technique may influence cerebral embolic risk. Numerous studies suggest that for all cardiac operations taken together, aortic cannulation results in lower stroke risk than does femoral cannulation and that axillary artery cannulation may confer an even lower risk. ${ }^{3,4}$ This trend is not consistently found in studies of repair of acute type A dissection. ${ }^{5,6}$ Femoral cannulation, however, may be particularly problematic in patients with high atherosclerotic burden. A recent meta-analysis published in the Journal demonstrated that in aortic surgery, central (as opposed to femoral) cannulation had an odds ratio of 0.71 (95\% confidence interval, 0.55-0.90) for permanent neurologic deficit. ${ }^{7}$ In addition, a higher incidence of stroke has been reported with femoral artery (as opposed to aortic) cannulation in mitral valve surgery. ${ }^{8}$ Plumbers, distillers, and hydraulics professionals will tell you that a good way to remove resistive deposits in pipes is to reverse the flow direction by "back flushing" the line. 9,10 Axillary cannulation was suggested at least 15 to 20 years ago, when various authors rationalized that (1) cannulation avoids direct contact with the aorta, (2) the flow diverts emboli originating in the aorta from embolizing to the right carotid artery, and (3) it eliminates the direct "sandblast" effect of the jet seen in aortic cannulation on the diseased aortic wall.

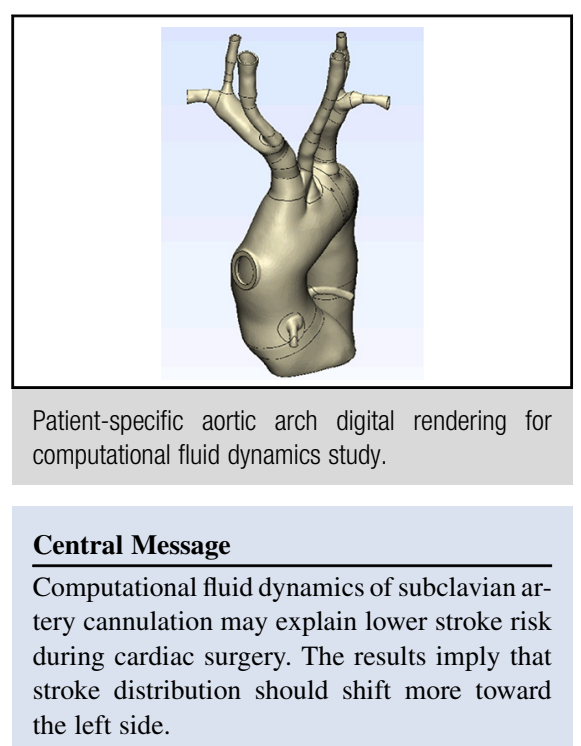

See Article page 480

In this issue of the Journal, Numata and coworkers ${ }^{11}$ use computational fluid dynamics to determine the pattern of streamlines in right subclavian artery versus aortic cannulation, with varying degrees of native ventricular outflow. Their experimental approach is technically sound. Their first finding, probably intuited by surgeons long ago, was that with right subclavian artery/axillary artery cannulation, essentially all the right carotid artery flow comes directly from the cannula without entering the aorta. As such, they argued, debris from the aorta could not embolize to the right carotid artery, at least during CPB. The pattern of streamlines entering the left carotid artery, however, depended on the specific arch anatomy and on the amount of antegrade aortic root flow in a less intuitively clear manner. Streamlines entering the left carotid artery could have a more circuitous path in the ascending aorta and arch, implying that emboli could be "picked up" and directed to the left carotid artery. This phenomenon could be studied with particle modeling and tracking techniques not incorporated in the study design of Numata and coworkers. $^{11}$

Hedberg and Engström ${ }^{12}$ calculated that 39.7\%, 24.7\%, and $11.9 \%$ of strokes appearing early after cardiac surgery occurred in the right, left, and bilateral hemispheres, respectively. The results of Numata and coworkers ${ }^{11}$ suggest that with axillary cannulation, the distribution of strokes should shift more to the left side-a testable 
hypothesis. Furthermore, the methodology of Numata and coworkers $^{11}$ is appealing because it suggests that computational fluid dynamics may be used preoperatively to inform relative embolic risk and determine an optimal cannula position and flow rate to mitigate the risk of cerebral embolization during CPB.

In any case, even a perfect pattern of flow during CPB will not mitigate the risk of embolization related to any cause before or after CPB. Nor will it obviate the risk of neurologic injury from causes other than aortic plaque embolization. The quest for "stroke-free" cardiac surgery should continue along all these lines.

\section{References}

1. Udesh R, Mehta A, Gleason TG, Wechsler L, Thirumala PD. Perioperative strokes and early outcomes in mitral valve surgery: a nationwide analysis. J Cardiothorac Vasc Anesth. December 7, 2016 [Epub ahead of print].

2. Zhao DF, Edelman JJ, Seco M, Bannon PG, Wilson MK, Byrom MJ, et al. Coronary artery bypass grafting with and without manipulation of the ascending aorta: a network meta-analysis. J Am Coll Cardiol. 2017;69:924-36.

3. Etz C, Plestis K, Kari F, Silovitz Bodian C, Spielvogel D, et al. Axillary cannulation significantly improves survival and neurologic outcome after atherosclerotic aneurysm repair of the aortic root and ascending aorta. Ann Thorac Surg. 2008;86:441-6; discussion 446-7.

4. Benedetto U, Mohamed H, Vitulli P, Petrou M. Axillary versus femoral arterial cannulation in type A acute aortic dissection: evidence from a meta-analysis of comparative studies and adjusted risk estimates. Eur J Cardiothorac Surg. 2015;48:953-9.

5. Klotz S, Bucsky BS, Richardt D, Petersen M, Sievers HH. Is the outcome in acute aortic dissection type A influenced by use of femoral versus central cannulation? Ann Cardiothorac Surg. 2016;5:310-6.

6. Abe T, Usui A. The cannulation strategy in surgery for acute type A dissection. Gen Thorac Cardiovasc Surg. 2017;65:1-9.

7. Benedetto U, Raja SG, Amrani M, Pepper JR, Zeinah M, Tonelli E, et al. The impact of arterial cannulation strategy on operative outcomes in aortic surgery: evidence from a comprehensive meta-analysis of comparative studies on 4476 patients. J Thorac Cardiovasc Surg. 2014;148:2936-43. e1-4.

8. Bedeir K, Reardon M, Ramchandani M, Singh K, Ramlawi B. Elevated stroke risk associated with femoral artery cannulation during mitral valve surgery. Semin Thorac Cardiovasc Surg. 2015;27:97-103.

9. Ellison D. Investigation of pipe cleaning methods. Denver: AWWA Research; 2003:3-32.

10. Russel I, Stewart G, eds. Whisky: technology, production and marketing. 2nd ed. Oxford: Elsevier; 2014:308-12.

11. Numata S, Itatani K, Kawajiri H, Yamazaki S, Kanda K, Yaku H. Computational fluid dynamics simulation of the right subclavian artery cannulation. J Thorac Cardiovasc Surg. 2017;154:480-7.

12. Hedberg M, Engström KG. Stroke after cardiac surgery-hemispheric distribution and survival. Scand Cardiovasc J. 2013;47:136-44. 